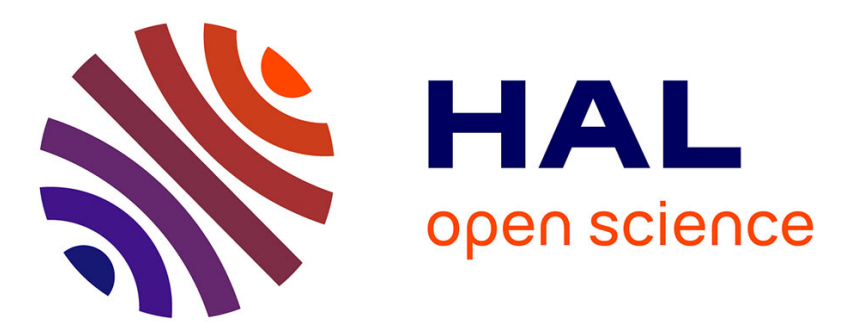

\title{
Online tests based on contributions provided by teachers and students during face-to-face lectures
}

\author{
Franck Silvestre, Philippe Vidal, Julien Broisin
}

\section{To cite this version:}

Franck Silvestre, Philippe Vidal, Julien Broisin. Online tests based on contributions provided by teachers and students during face-to-face lectures. 15th IEEE International Conference on Advanced Learning Technologies (ICALT 2015), Jul 2015, Hualien, Taiwan. pp. 29-33. hal-01377329

\section{HAL Id: hal-01377329 \\ https://hal.science/hal-01377329}

Submitted on 6 Oct 2016

HAL is a multi-disciplinary open access archive for the deposit and dissemination of scientific research documents, whether they are published or not. The documents may come from teaching and research institutions in France or abroad, or from public or private research centers.
L'archive ouverte pluridisciplinaire HAL, est destinée au dépôt et à la diffusion de documents scientifiques de niveau recherche, publiés ou non, émanant des établissements d'enseignement et de recherche français ou étrangers, des laboratoires publics ou privés. 




\section{Open Archive TOULOUSE Archive Ouverte (OATAO)}

OATAO is an open access repository that collects the work of Toulouse researchers and makes it freely available over the web where possible.

This is an author-deposited version published in : http://oatao.univ-toulouse.fr/ Eprints ID : 15338

The contribution was presented at ICALT 2015 :

http://www.ask4research.info/icalt/2015/

To cite this version : Silvestre, Franck and Vidal, Philippe and Broisin, Julien Online tests based on contributions provided by teachers and students during face-to-face lectures. (2015) In: 15th IEEE International Conference on Advanced Learning Technologies (ICALT 2015), 6 July 2015 - 9 July 2015 (Hualien, Taiwan, Province Of China).

Any correspondence concerning this service should be sent to the repository administrator: staff-oatao@listes-diff.inp-toulouse.fr 


\title{
Online tests based on contributions provided by teachers and students during face- to-face lectures
}

\author{
Franck Silvestre, Philippe Vidal, Julien Broisin \\ Institut de Recherche en Informatique de Toulouse \\ University of Toulouse III \\ Toulouse, France \\ \{franck.silvestre,philippe.vidal,julien.broisin\}@irit.fr
}

\begin{abstract}
Our previous work has introduced the "TsaapNotes" platform to increase the motivation and engagement of students in the process of collaborative note taking during lectures. In this paper, we introduce the approach "Notes as Feedback" which consists of recycling interactive questions asked during a lecture in order to semi-automatically build computer based self-assessment tests where feedback provided to students is based on the notes taken by students. A first experimentation on a group of 54 students enrolled in a computer science Master course helped to highlight the benefits of this work: increased participation in note-taking, a massive engagement of students to play the self-assessment tests, and improved student results at the final exam.
\end{abstract}

Collaborative note taking; audience response system; computer based assessment; self-assessment; feedback

\section{INTRODUCTION}

Several studies have shown the benefits of using collaborative note taking systems [12], micro-blogging systems [11] or audience response systems [3] during lectures. These three kinds of system have their own characteristics: micro-blogging is social-network oriented [13] and can be used with any Internet connected devices (laptops, tablets, smartphones, etc.) more and more available in classrooms [5]; collaborative note taking systems allow annotation of numeric resources, such as slides, presented during lectures [12], [19]; finally, audience response systems are better known to increase the engagement of the students during a lecture [6] and give the teacher opportunities to trigger and arbitrate constructive discussions among students [20]. In summary, collaborative construction of knowledge and increased engagement of students are the main advantages given by these systems.

We presented in [19], Tsaap-Notes, a collaborative note taking platform based on a micro-blogging system and embedding an audience response system. The results of first experimentations on the use of the platform show that combining the features of each system the Tsaap-Notes way reinforces the benefits of each system used separately. More precisely, during the lecture, students take more notes after the presentation of the results obtained on an interactive question asked through the audience response system: the discussion among students and teacher triggered by the presentation of the results, i.e. the feedback from this presentation, is summarised and transcribed by the students in the form of notes.

Some studies [15], [18] show that computer based assessments facilitate the provision of frequent formative assessments to large cohorts of students. Also, the quality of the feedback provided to the students in the context of their work or of their assessment results is a key factor for successful learning [1], [7], [9]. D. Nicol and D. MacfalaneDick [17] recommend the use of online tests so that feedback can be accessible anytime, from any place and as many times as students wish.

In this paper, we present our approach called Note as feedback designed to generate online self-assessment tests in a semi-automatic way by recycling the questions asked by the teacher and the notes taken by the students during a lecture. Students can access and run these online tests in the learning management system (LMS) of their institution; the feedback provided by the LMS is based on the notes taken by the students during the lecture.

The paper is organized as follows: section II reviews the main features provided by Tsaap-Notes which the Note as Feedback (NaF) approach is based on; section III shows the motivations for the $\mathrm{NaF}$ approach; Section IV presents in detail the design and implementation of the $\mathrm{NaF}$ feature in Tsaap-Notes; finally we report a first experimentation with Master students of the University of Toulouse III before concluding and presenting some future work.

\section{THE TSAAP-NOTES PLATFORM}

Tsaap-Notes has been designed for collaborative annotation of the course material by students during lectures. The platform is presented in detail in [19], we review in this section only its main features.

Tsaap-Notes is a web application (https://notes.tsaap.eu/tsaap-notes/) compliant with any device able to connect to the Internet (smartphone, laptop, tablets, etc.). Inspired by many web 2.0 and social network applications, each owner of an account on Tsaap-Notes can post a note, put into context a note with hash tags, mark a note as favorite, vote for a particular note or answer directly to a note posted by another user. Furthermore, Tsaap-Notes can easily be embedded in any web tools. For example, Tsaap-Notes has been integrated in a system for online 
presentation of a course material [19], allowing students to annotate directly a fine piece of the course material (i.e. a particular slide). Fig. 1. illustrates the user interface of Tsaap-Notes embedded in a web page displaying a slide.

\section{Logiciel libre / logiciel Open Source}
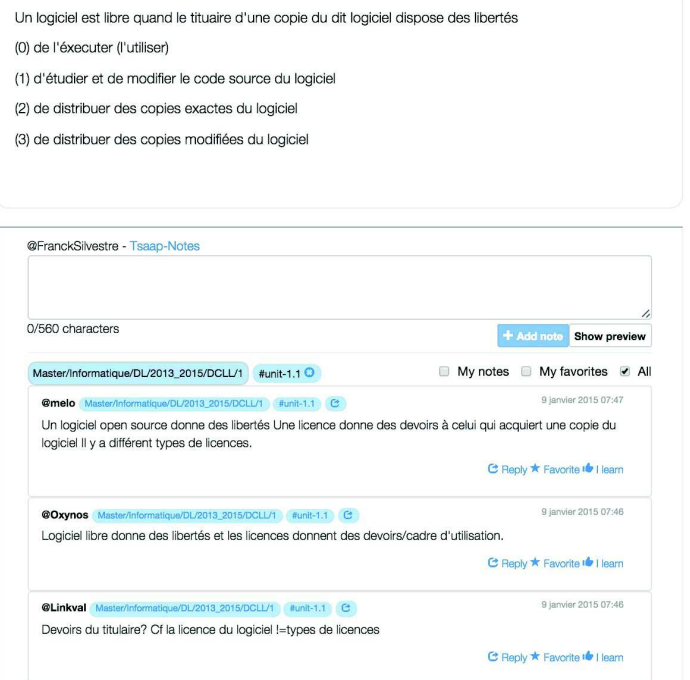

Figure 1. Tsaap-Notes embedded in web page displaying a slide

The approach Notes as Feedback presented in the next sections is based on two key features of Tsaap-Notes: (1) the ability to gather notes into a same feed, what we called a scope in Tsaap-Notes, and (2) the audience response system. A scope is characterized by a name, a description and a URL (optional). It can be used to reference any kind of learning artifacts: a web resource, a course, an activity, a topic, etc. Any owner of a Tsaap-Notes account can create as many scopes as he wants and can indicate when creating a scope if he is a teacher or a learner around this scope. Fig. 5. illustrates a scope referencing a course hosted in the LMS of the University Toulouse III.

The "Note as question" feature allows a teacher to post a note that is in fact an interactive question. The note must conform to the Moodle Gift format (https://docs.moodle.org/23/en/GIFT format) in order to be interpreted as a question by the audience response system embedded in Tsaap-Notes. Fig. 2. shows an example of a question written in Gift format. We adopted the Moodle format because our university uses it as LMS; in fact, any other format, such as IMS QTI [10], could be used to describe a question in Tsaap-Notes. During the lecture, the teacher controls the sequence of the student activity around a question: he decides when to start the survey, when to stop it and when to present the results to the audience. Fig. 3. shows the user interface presented to a student to answer a question while Fig. 4. illustrates the presentation of the results and shows a note taken by a student after this presentation. This note explains the reason why " 8 " was the good result; in fact, such a note is the transcription of all or only part of the feedback provided to the students after the presentation of the results.

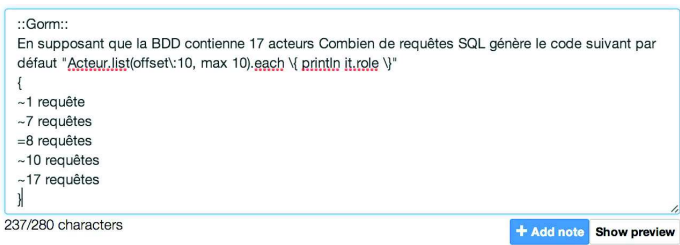

Figure 2. Edition of a question following the Moodle Gift forma

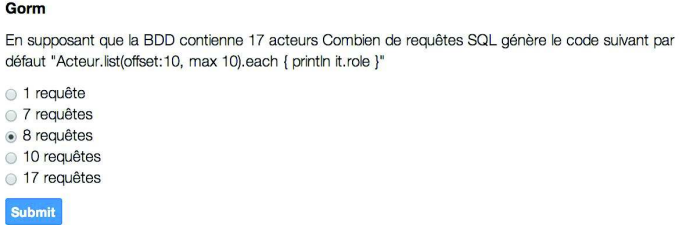

Figure 3. User interface to submit an answer

Tsaap-Notes, combining an audience response system with a collaborative note taking tool, stimulates (1) constructive interactions between teacher and students after the presentation of the results on an interactive question and (2) the appropriation of this feedback by the students through the note taking. In order to facilitate the preparation of students for their exam, we decided to recycle questions and notes relative to these questions to semi-automatically create online self-assessment tests.

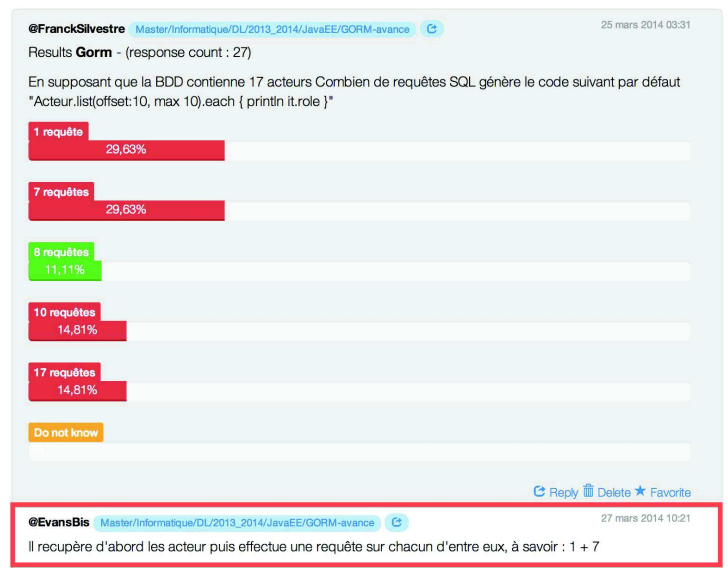

Figure 4. Presentation of the results with feedback transcription

\section{WhY THE "NOTE AS FEEDBACK" APPROACH ?}

The question of feedbacks provided to the student during a computer-based self-assessment is tricky. In traditional online LMS (Moodle, Chamilo, Claroline, Blackboard or any IMS QTI compliant platform), the feedback is, by default, minimalist: for each question, the feedback consists of the score of the student for the current question and of the presentation of the correct answer. If the author of the test takes the trouble to specify additional explanations (general 
or even for each possible choice) then the LMS is able to provide the students with this additional feedback. This way of managing the feedback raises some issues: (1) the manual completion of the feedback by the teacher for each question is time consuming so that it is rarely done, (2) the feedback provided by the system is the same for all students [2], (3) the feedback given by the teacher may not be understood by the student because it is not written in the student dialect [4], [8], and finally (4) the feedback is independent of the initial learning context while this characteristic offers guaranties on its quality [2]. Also, because of the constant increase of students enrolled at the university, the idea of a single teacher providing a quality feedback to each of his students is simply not sustainable [17]. The use of student productions as feedback has already been explored. For example, in [14], messages posted by students on a bulletin board are archived by the teacher to be reused as source of feedback for other students. The experimentations described in [16] promote the use of audience response system during lectures to build feedback coming either from the teacher or the learners.

The Note as Feedback approach initiated in our work consists of reusing the notes taken by students during a lecture as source of feedback provided to these same students in the context of self-assessment. With this approach (1) the teacher doesn't have to enter the feedback manually (although the teacher is always the indirect source of the feedback), (2) a specific feedback corresponding to what the students transcribed during the lecture is delivered to the students (different lectures addressed to different group will produce different feedbacks to the students of each group), (3) improves the chance that the feedback will be understood by the students because it comes from their own production, written in their dialect, and (4) provides a direct connection between the feedback and the corresponding initial learning context (the initial lecture or activity where the students took notes).

\section{TSAAP-NOTES AND THE GENERATION OF SELF- ASSESSMENT TESTS}
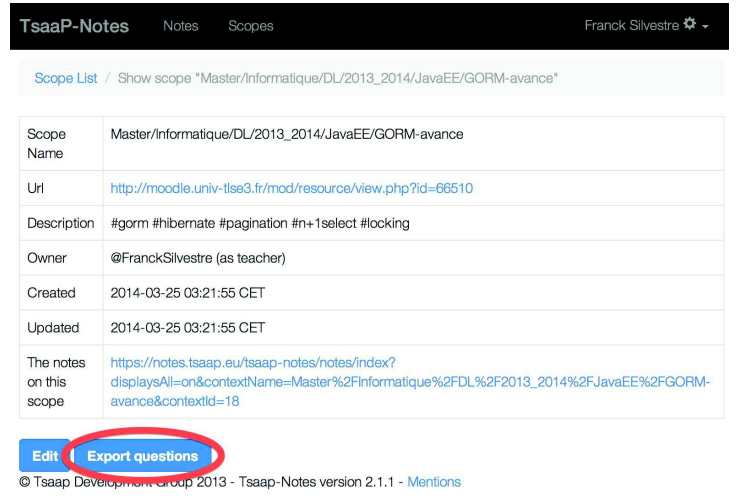

Figure 5. Export of the questions relative to a scope

In order to help the creation of a self-assessment test based on the interactive questions asked during the lecture, we designed and implemented the "Export questions" feature in Tsaap-Notes. The owner of a scope (the teacher in our case) can export all questions linked to his scope; Fig. 5. illustrates the user interface of Tsaap-Notes allowing the teacher to trigger the export. The export engine finds all questions for the current scope and then, for each question, finds all notes taken by the students on the current processed question. These notes are injected as general feedback in the specification of the question. As mentioned in section II, the export function generates a file that conforms to the Moodle Gift format. Therefore, the generated file can be imported in any Moodle platform through the import function that a teacher can use to populate the question bank of a course. The teacher can modify the specification of an imported question using the edition form provided by Moodle (see Fig. 6.). The field "General feedback" is automatically filled with the notes taken by the students during the initial lecture. So, when the students run a test on Moodle containing such a question, they receive for each question a feedback with the score they obtained on the question, the correct response and the notes they took during the lecture. Fig. 7. shows the user interface provided by Moodle to display the feedback addressed to a student who ran a self-assessment test.

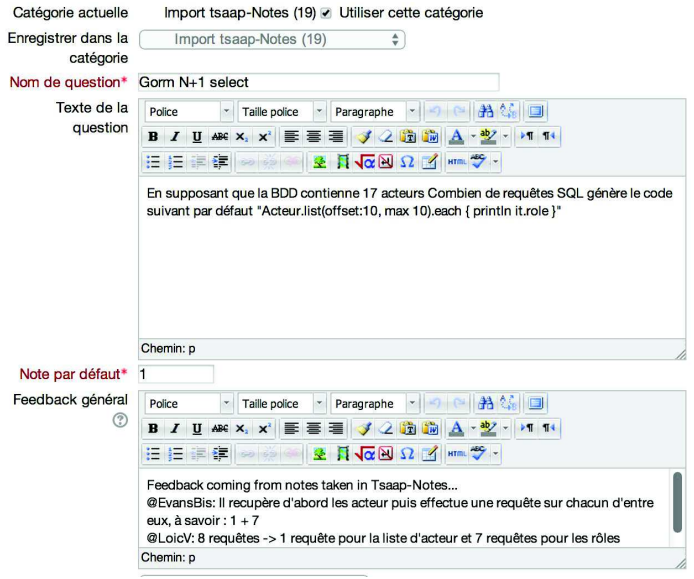

Figure 6. Edition in Moodle of a question imported from Tsaap-Notes



Figure 7. Display of the feedback addressed to a student in Moodle

The "Notes as feedback" approach gives the teacher the opportunity to reuse the material built by himself (the questions) and by the students (the taken notes) during lectures so that, he has only to select the imported questions coming from Tsaap-Notes to compose the self-assessment test. Also, students can receive a quality feedback, meaning an understandable feedback connected with the lecture they took part in while the teacher don't have to work on it 
outside the lecture (no need for him to fill complementary explanations for each question in the form edition).

The "Note as feedback" system allows the introduction of a computer based self-assessment activity that gives the students the opportunity to work anytime, from anywhere, as many times as they want. Furthermore, these selfassessments add value to the students' engagement during lectures by recycling the notes they took during an activity mainly directed by the teacher.

\section{FIRST EXPERIMENTATION}

The "Notes as Feedback" system was tested on a group of 54 students enrolled in the first year of a computer science Master course entitled "Developing Applications with Java EE". Out of these 54 students, only 35 were there during the 10 hours of lecture, which is an average rate of $65 \%$ of participation. The teacher asked students 82 interactive questions via the Tsaap-Notes platform. 26 students answered the questions, which corresponds to an average rate of $74 \%$ of the audience of the lecture.

We show in this section the results of this first experimentation: an increase in the number of notes taken by students on the interactive questions, a large participation in the self-assessment tests, and the improvement of students results at the final exam.

\section{A. Participation in note taking}

At the beginning of the experimentation (during the first hour of lecture), the Tsaap-Notes platform was briefly introduced to students. The students were informed that the interactive questions asked by the teacher during the lecture would be reused in self-assessment tests hosted in the Moodle platform. During the first 6 hours, the export feature with the recycling of the notes taken by the students was not available in Tsaap-Notes; therefore, the students were not informed that their notes would be reused in the selfassessment tests. On this first period of the experimentation, students took few notes on the interactive questions: for 55 questions, only 6 notes were posted, which corresponds to a rate of $10 \%$. At the beginning of the seventh hour of lecture, students were informed that the notes they take would be reused in the self-assessment tests. During the 4 last hours of lecture, 27 questions were asked; the students posted 14 notes, which corresponds to a rate of $52 \%$.

The first notable result of this experimentation is that the reuse of notes taken by students in the self-assessment tests significantly strengthened the note taking on the interactive questions: concrete utility of taken notes encouraged students to take notes.

\section{B. Participation in self-assessment tests}

Two sets of tests were created on the Moodle workspace corresponding to the course concerned by the experimentation: the first set did not contain any notes taken by the students while in the second set, the notes taken by the students were used as the source of the feedback. Tests without notes where ignored by almost all students: only 4 students ran these tests and then 3 of them switched to second set of tests. 47 students, which correspond to a rate of
$87 \%$ of the students enrolled in the course, ran the selfassessments tests containing feedback coming from taken notes.

Here is a second notable result: all students prefer running tests with feedback based on their notes, rather than running tests without feedback. We can infer from this observation that students consider as really useful the feedback based on their own taken notes provided during the computer based self-assessment tests.

Let's notice that, in our experimentation, we did not consider creating a set of tests with feedback entered by the teacher. This option has been intentionally discarded because our goals consist of (1) addressing issues coming from this traditional approach where the teacher enter the feedback for each question (cf. section III: the cost of manual specification of the feedback and the risk of an inappropriate feedback, etc.), and (2) increasing the engagement of students in the note taking process by giving value to their production.

\section{Results in the final exam}

At the end of the course, a test containing 102 questions and counting for $30 \%$ of the final grade was submitted to the students. In these 102 questions, 82 questions came from Tsaap-Notes. The numerical values in this set of questions were modified in order to limit the rote learning effect. The results in 2014 were radically different from those obtained in the previous year (the course in its actual form has only been existing for two years): the average mark in the test was $17 / 20$ with a standard deviation of 1.48 (Fig. 8. illustrates the distribution of the grades in 2014), while the average ones in the previous year was 11.92 with a standard deviation of 3.26 .

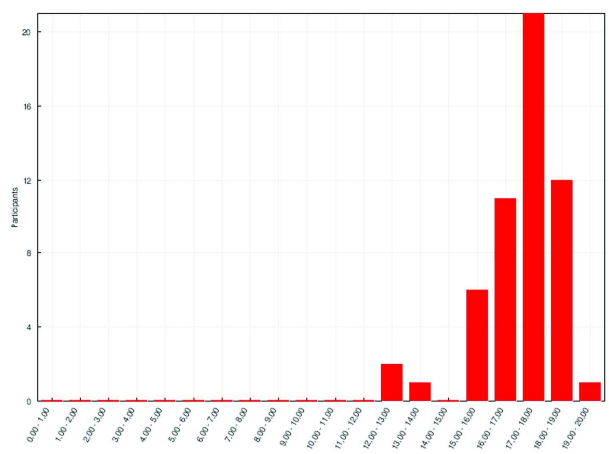

Figure 8. Distribution of grades in the computer based assessment in 2014

The system used in the context of our teaching, which integrates the platform Tsaap-Notes and a set of selfassessment tests, has led to a remarkable increase in student performance on the computer based assessment at the final exam. The comparison of the results above, however, must be tempered by the significant differences presented by the two summative assessments: in 2013, the test consisted of 54 questions only (102 in 2014) and only 20 questions were common to both exams. Also, it is hard to distinguish, in the system, what had the strongest influence: in 2013, the Tsaap- 
Notes platform was not integrated within the teaching, and the self-assessment tests were not available to students.

\section{CONCLUSION AND PERSPECTIVES}

The Tsaap-Notes platform combines micro-blogging features with audience response system in order to foster collaborative note taking by students during lectures. Especially, Tsaap-Notes gives the students the opportunity to take notes as a whole or to focus on a specific part of the course material such as a slide or an interactive question.

In this paper, we presented the new feature called "Notes as feedback" which consists of recycling the questions and notes produced in Tsaap-Notes in order to semiautomatically generate computer based self-assessment tests. The tedious task of creating such test is now limited: teachers only have to create the test; they don't have to elaborate the questions that make up the test. These tests, carried out in a learning management system such as Moodle, provide the students a feedback based on the notes previously taken by these students.

The results coming from the first experimentation are encouraging: (1) students are more engaged in note taking when these notes are reused in self-assessment tests; (2) selfassessment tests resulting from the "Notes as feedback" approach are massively played by the students; (3) the implementation of the whole system (Tsaap-Notes and selfassessment tests) has a very positive impact on the results of the students in their final computer based assessment.

These results lead us to continue our research on semiautomatic generation of computer based assessment tests reusing student notes as the source of feedback. The approach developed in Tsaap-Notes is a first step in the personalization of computer based self-assessment tests. Indeed, the tests generated from Tsaap-Notes are built with questions asked by the teacher during lectures and the results and answers of each student are recorded. The notes taken by the students on the displayed results for these questions are recorded too. All these elements could be used to provide each student with a personalized set of tests taking into account his profile. In the tests generated by Tsaap-Notes, the feedback is already more than a generic production identical for all students: the students, in the context of lectures they participate in, build the feedback. While this contextualization of the feedback corresponds only to a group level adaptation (a group of students participating in the same lecture), some research could allow us to adapt the feedback at each person's level inside the group. In our current work, we try to answer the following questions: how to build a student profile in the situation of self-assessment? How to extract from the elements recorded in Tsaap-Notes the relevant information to build personalized tests? Which algorithms and recommendation mechanisms should be implemented?

\section{REFERENCES}

[1] P. Black and D. Wiliam, "Assessment and Classroom Learning," Assess. Educ. Princ. Policy Pract., vol. 5, no. 1, pp. 7-74, Mar 1998.

[2] J. Bull and C. McKenna, Blueprint for computer-assisted assessment. 2004

[3] J. Caldwell, "Clickers in the large classroom: Current research and best-practice tips," CBE-Life Sci. Educ., 2007.

[4] K. Chanock, "Comments on essays: do students understand what tutors write?," 2000.

[5] M. Ebner, C. Lienhardt, M. Rohs, and I. Meyer, "Microblogs in Higher Education-A chance to facilitate informal and processoriented learning?," Comput. Educ., 2010.

[6] S. Gauci and A. Dantas, "Promoting student-centered active learning in lectures with a personal response system," $A d v$. ... 2009.

[7] J. Hattie and R. Jaeger, "Assessment and classroom learning: A deductive approach," Assess. Educ., 1998.

[8] R. Higgins, BE MORE CRITICAL: RETHINKING ASSESSMENT FEEDBACK. 2000

[9] R. Higgins, P. Hartley, and A. Skelton, "The conscientious consumer: reconsidering the role of assessment feedback in student learning," Stud. High. Educ., vol. 27, no. 1, 2002.

[10] IMS Global Learning Consortium, "IMS Question \& Test Interoperability Specification.” 2012.

[11] R. Junco, G. Heiberger, and E. Loken, "The effect of Twitter on college student engagement and grades," J. Comput. Assist. ..., 2011 .

[12] M. Kam, J. Wang, A. Iles, E. Tse, and J. Chiu, "Livenotes: system for cooperative and augmented note-taking in lectures," Proc. ..., 2005

[13] H. Kwak, C. Lee, H. Park, and S. Moon, "What is Twitter, social network or a news media?," ... 19th Int. Conf. ..., 2010.

[14] M. Lea, "Computer conferencing and assessment: new ways of writing in higher education," Stud. High. Educ., 2001.

[15] T. Miller, "Formative computer-based assessment in higher education: The effectiveness of feedback in supporting student learning," Assess. Eval. High. Educ., 2009.

[16] D. Nicol and J. Boyle, "Peer Instruction versus Class-wide Discussion in large classes : a comparison of two interaction methods in the wired classroom," Stud. High. Educ., vol. 28, pp. 458-473, 2003 .

[17] D. Nicol and D. Macfarlane-Dick, "Formative assessment and self-regulated learning : A model and seven principles of good feedback practice .," Stud. High. Educ., pp. 1-19, 2006.

[18] C. Ricketts and S. Wilks, "Improving student performance through computer-based assessment: Insights from recent research," Assess. Eval. High. Educ., vol. 27, no. 5, 2002.

[19] F. Silvestre, P. Vidal, and J. Broisin, "Tsaap-Notes--An Open Micro-blogging Tool for Collaborative Notetaking during Faceto-Face Lectures," ... Learn. Technol. (ICALT), ..., 2014.

[20] M. Uhari, M. Renko, and H. Soini, "Experiences of using an interactive audience response system in lectures," BMC Med. Educ., 2003 